\title{
Comments on Badejoko et al.: Overflow urinary incontinence due to bladder stones
}

\author{
Ayman Mahdy
}

Published online: 22 July 2014

(C) The International Urogynecological Association 2014

Dear Editor,

I read with interest the article by Badejoko et al. [1]. The authors reported an interesting case of multiple bladder calculi in a woman who presented with urine incontinence. I would like to share a few comments related to this article.

First, although I agree with the treatment offered, I disagree with the authors' diagnosis of overflow incontinence. Overflow incontinence is the type of incontinence associated with urine retention. There is no support for the diagnosis of urine retention in this case. The authors based their diagnosis solely on the patient's symptoms. There is a large volume of urology literature that suggests these symptoms are actually typical for bladder stones. The literature further supports the fact that these symptoms are primarily related to bladder irritation and not urine retention [2-4]. As a matter of fact, large bladder stones are very rarely a cause of urine retention [5]. Furthermore, there was no objective evidence of urine retention in the study. There was no reported use of bladder ultrasound, bladder scan, straight catheter, etc., to prove the diagnosis. I believe the correct diagnosis is urgency urinary incontinence secondary to bladder irritation by bladder stones.

Second, the authors commented on the value of intravenous pyelogram (IVP) in the setting of urine incontinence based on their findings in this particular case. Although the IVP has well-established clinical value in urological imaging, I do not see how IVP helped in this particular case. Bladder stones do not necessarily need an IVP for diagnosis. They can simply be diagnosed using a regular abdominal X-ray or bladder ultrasound. The authors would have an argument if the IVP findings supported their diagnosis of urine retention. Those findings may include vesico-ureteral reflux and/or large post-void residual volume seen in the post-evacuation film. Unfortunately, the IVP showed only bladder stones and was normal otherwise, and as reported by the authors. This again argues against the diagnosis of urine retention and overflow incontinence. Also, the X-ray figure shown in the article is actually for a scout film, not an IVP. There is no contrast seen in the film presented.

Finally, multiple bladder stones in adults are almost always secondary to an underlying pathological condition of the bladder [5].

I would suggest that this patient receives further evaluation for possible underlying pathological conditions such as neurogenic bladder.

Financial disclaimers None.

Conflicts of interest None.

\section{References}

1. Badejoko OO, Salako AA, Egharevba P (2014) Overflow urinary incontinence due to bladder stones. Int Urogynecol J 25:425-427. doi:10.1007/s00192-013-2153-4

2. Smith JM, O'Flynn JD (1975) Vesical stone: the clinical features of 652 cases. Ir Med J 22:85-89

3. Douenias R, Rich M, Badiani G et al (1991) Predisposing factors in bladder calculi: review of 100 cases. Urology 37:240-245

4. Irer B, Aslan G, Cimen S et al (2005) Development of vesical calculi following tension-free vaginal tape procedure. Int Urogynecol J 16 : 245-246

5. Benway BM, Bhayani SB (2012) Lower urinary tract calculi. In: Campbell-Walsh urology (10th ed). Elsevier, Philadelphia, pp 2509-2518

\footnotetext{
A. Mahdy $(\bowtie)$

Division of Urology, Department of Surgery, University of

Cincinnati, Cincinnati, OH, USA

e-mail: mahdyan@uc.edu
} 